\title{
Researching a Capacity Model for Multilane Roundabouts with Negotiation of the Right-of-Way between Antagonist Traffic Flows
}

\author{
Orazio Giuffre ${ }^{1}$, Anna Granà ${ }^{1}$, Tullio Giuffrè ${ }^{2} \&$ Roberta Marino ${ }^{1}$ \\ ${ }^{1}$ Università degli Studi di Palermo, iale delle Scienze, Palermo, Italy \\ ${ }^{2}$ Faculty of Engineering and Architecture, Kore University of Enna, Cittadella Universitaria, Italy \\ Correspondence: Anna Granà, Department of Civil, Environmental and Aerospace engineering, Università degli \\ Studi di Palermo, Viale delle Scienze, Ed. 8, Palermo 90128, Italy. Tel: 39-91-2389-9718. E-mail: \\ anna.grana@unipa.it
}

Received: March 4, 2012

Accepted: March 26, 2012 Online Published: May 1, 2012

doi:10.5539/mas.v6n5p2

URL: http://dx.doi.org/10.5539/mas.v6n5p2

\begin{abstract}
This article summarizes a research program designed to assess operating conditions through capacity estimation at not-conventional roundabouts characterized by a central island with a large diameter and by two (or more) entering and circulating lanes. Although giving priority to vehicles on circulatory roadway is the nominal operating rule, on-field observations highlighted that in some infrastructural schemes of the type considered in this research drivers negotiate the right-of-way according to a consensus pattern that alternates between antagonist traffic flows, similarly to that observed at all-way-stop-controlled intersections. Considering the peculiarity of the way of working at roundabout schemes being examined, as well as difficulties faced in the application of models based on gap-acceptance theory to evaluate performances, an analytical capacity model derived from field observations was proposed for multilane not conventional roundabouts.

Drawing inspiration from the iterative procedure proposed for capacity estimates at all-way-stop-controlled intersections, a calculation algorithm organized in 5 subsequent computational steps was developed in order to evaluate capacity at each entering/circulating lane for the type of roundabouts examined in this research. Results compared to those calculated by models for modern roundabouts show the effect on estimates of capacity raised by a more realistic operating pattern and indicate that the capacity model may be able to estimate parameters useful for planning and design purposes.
\end{abstract}

Keywords: multilane roundabouts, capacity, headway

\section{The Background}

Several studies have shown that among engineering treatments used to solve the intersection of three or more roads, roundabouts are solutions favorable in terms of traffic safety and capacity. Improvements in safety performances are due to geometric design features and their composition, which help to reduce travel speeds and to provide consistent speeds by using entry deflection. Together with the lower speed of entering vehicles and their curved paths through the roundabout, the reduction in the number of conflict points with respect to other at-grade intersection patterns, however regulated, can contribute to reduce the likelihood and severity of collisions when occur. In terms of operational performances, roundabouts can handle traffic volumes through the intersection more efficiently, making lower overall delays compared to signalized intersections under the same traffic volumes, as well as roundabouts can provide a higher capacity than all-way stop-controlled intersections. Entering drivers, indeed, are required only to give priority to one-way traffic travelling counterclockwise around the central island and not to wait for a green light to get through the intersection.

The flexibility of elements shaping the intersection scheme has favored new roundabout installations at different levels of the road network. Roundabouts are designed to carry both low and high traffic volumes and then operations can include a lot of road situations. High volume roundabouts are often integrated into complex junctions characterized by a large diameter of the central island and by two (or more) lanes at entries and in the circulatory roadway. In general new roundabout installations and conversion of an existing intersection in a roundabout must be justified on the basis of trade-offs between operational and safety performance improvements. Despite the roundabouts are able to improve some problems compared to other at-grade intersections, taking into account size, the context of installation and site constraints, not all roundabouts have 
the same performances. Multilane roundabouts present additional conflicts compared to single-lane roundabouts and also introduce additional complexity in decision making: drivers cannot always see the exit or drivers have to gradually change direction because the intersection is curved; drivers can be so misguided as to origin and destination. And again, physical, topographical and architectonic constraints, particularly in urban areas, can affect operations at roundabout installations, as well as at all the other intersections; so atypical roundabout layouts (i.e. with regard to design features and performances) can operate in a very different way from conventional intersections. According to Rodegerdts et al. (2010) several real-world conditions can affect the accuracy of a given modeling technique or the type of analysis being applied for analyzing roundabout performances. With specific reference to urban not conventional roundabout installations, operations can be often characterized by random components due to user unconventional behaviors; actually, most of entering drivers can show irregular behavior in yielding and, in parallel, circulating vehicles can behave irrationally, surrendering their right-of-way. As a consequence, the univocal interpretation of operations and the estimate of behavioral parameters at not conventional roundabouts can be compromised by the application of usual methods for modern roundabouts, as those based on gap-acceptance theory, leading to very rough results (Granà \& Giuffrè, 2005).

\section{Introducing Roundabouts with Negotiation of the Right-of-Way between Antagonist Traffic Flows}

Field observations carried out on a sample of multilane not conventional roundabouts operating in the road network of Palermo City, Italy, have shown frequent inversions of right-of-way between entering and circulating vehicles even though the entry maneuver is regulated by the give-way sign; in particular it was observed that traffic performs negotiating the right-of-way between vehicles entering from the approach and those streaming in the circulating lanes, similarly to what happens at all-way stop-controlled intersections. Reference should be made to Chapter 17 of the 2000 edition of the Highway Capacity Manual, as well as to Chapter 32 of the 2010 edition of the same Manual for acquiring details to calculate all-way stop-controlled intersection operations. Here it refers only briefly that at an all-way stop-controlled intersection the rate of departure from the subject approach is controlled by the presence or not of vehicles on conflicting (or on opposing) approaches. Moreover the behavioral parameter describing operations is the headway between consecutively departing subject approach vehicles (i.e. drivers consecutively departing from the stop line at the entry approach); the departure headway is based on the probability of occurrence of each of the possible degree-of-conflict cases among subject approach vehicles and vehicles on the other intersection approaches, under which an all-way stop-controlled intersection can operate (Kyte \& List, 1999). A further and interesting theoretical approach for determining capacity at all-way stop-controlled intersections was presented by $\mathrm{Wu}$ (2000). This procedure, based on the addition-conflict-flow method developed from graph theory, can handle most common lane configurations in the real world including multilane approaches.

Operational conditions at the examined multilane not conventional roundabouts are similar but more complex than those ones observable at all-way stop-controlled intersections for several reasons: in fact, at multilane not conventional roundabouts, drivers moving on circulating lanes are not required to stop before proceeding into the intersection; frequent inversions of right-of-way between entering and circulating vehicles occur (most of entering drivers show irregular behavior in yielding, because they do not stop to give priority to circulating vehicles that have right-of-way); some movements are not conflicting between entering vehicles and circulating vehicles (e.g. vehicles approaching the intersection from the outer entry lane or from the inner lane of the circulatory roadway); in quite all cases driver behavior is strongly influenced by the lane occupied by vehicles, both on the subject approach and on the conflicting approach. Considering operational affinities with all-way stop-controlled intersections, the idea arose to consider these issues and to determine whether they are significant in the analysis of operations at multilane not conventional roundabouts. Further details to explain the entry conditions of vehicles into the circulatory roadway at multilane not conventional roundabouts are delivered in Giuffrè et al. (2007a).

In this paper a computational framework for appraising performance parameters (i.e. capacity) at not conventional roundabouts characterized by a central island with a large diameter and by two (or more) entering and circulating lanes is proposed. Operations at these schemes were modeled starting from a discrete number of saturation headway values, each reflecting a different degree of conflict faced by the subject approach driver (i.e. by the driver at the stop line of the entry approach or at the similar ideal stop line sited on the circulatory roadway, in turn). Each approach at multilane not-conventional roundabouts, here examined, is analyzed as an all-way stop-controlled intersection approach, but it is a one-way street. Thus the headway for a departing subject approach vehicle depends on the degree of conflict experienced with vehicles on the conflicting approach (i.e. the entry when the circulatory roadway is the subject approach or the circulatory roadway when the entry is 
the subject approach in turn). The exploratory analysis of on-field data and the application to a case study allowed to support the methodology proposed to derive the analytical procedure for capacity computations. Considering the interdependence of traffic flows on intersection approaches, the need for iterative calculations to obtain stable estimates of capacity was taken into account. The development of a 5-step iterative procedure requested a preliminary regression of traffic data to estimate saturation headways that cannot be directly observed, because operating conditions in which they could be observable rarely occur and suitable traffic operations to observe them not take enough time to make reliable measurements.

Starting from these considerations, section 3 focuses on the analysis method proposed for appraising performances at multilane not conventional roundabouts. Section 4 describes steps taken in modeling capacity and then section 5 discusses the application of the analytical procedure to a case study, referring the major results and possible future developments of the research.

\section{A Framework for Capacity Appraisal at Multilane Not Conventional Roundabouts}

In analogy to how all-way stop-controlled intersections operate, at a generic approach of a multilane not conventional roundabout, the headway experienced by vehicles on the subject approach lanes (the circulatory roadway or the entry in turn) depends on the degree of conflict with vehicles on the conflicting approach lanes (i.e. the circulatory roadway if the entry is the subject approach or the entry if the circulatory roadway is the subject approach); it is also a function of the number of vehicles faced by the subject approach driver and of the number of lanes at the approaches. At a generic approach of a multilane not conventional roundabout just two degree-of-conflict cases can be faced by entering or circulating vehicles on the subject approach: i) degree-of-conflict case (1/0): no vehicle is present at circulating lanes (or at entry); ii) degree-of-conflict case $(3 / *)$ : one vehicle (or more vehicles) is (or are) present at circulating lanes (or at entries). This second case can be split into different sub-cases basing on the number of vehicles on conflicting approach lanes. Therefore, in the general case of an approach with three entering/circulating lanes, eight possible combinations of degree-of-conflict cases can be considered, as it will be explained shortly in this section. According to what reported by Richardson (1987), Kyte et al. (1997) and HCM (2000), the departure headway is a function of the saturation headway distribution as expressed by:

$$
h_{d}=\sum_{i=1}^{n} P(i) \times h_{s i}
$$

where:

$P(i)=$ the probability of the degree-of-conflict case $i$;

$h_{s i}=$ saturation headway for the degree-of-conflict case $i$, given the traffic streams and geometric features of the intersection approach;

$i=$ each combination of the $n$ degree-of-conflict cases.

It must be said that, according to HCM 2000 (chapter 17) the departure headway can be measured on-field by surveying the driver waiting time at the stop line position during the analysis period (i.e. service time) and the time taken by the following driver to move to the stop line after the previous vehicle is departed from the stop line (i.e. the move-up time), as follows:

$$
h_{d}=t_{s}+m
$$

where $t_{s}$ is the service time, (s), and $m$ is the move-up time, (s).

The probability of each degree-of-conflict case $P(i)$ can be computed starting from the equation:

$$
P(i)=\prod_{L z} P\left(a_{L z}\right)
$$

where:

$L_{z}=$ a conflicting approach lane, where $z=1,2,3$ at a multilane not conventional roundabout with three entering lanes and three circulating lanes;

$a_{L z}=$ a value equal to 1 is a vehicle present in the lane; a value equal to 0 is no vehicle present in the lane;

$P\left(a_{L z}\right)=$ the probability there is or not a vehicle at a generic lane of the conflicting approach or the probability of $\mathrm{a}_{\mathrm{Lz}}$; it is also defined in any combination $i$ as a function of $V_{L z}$ (the lane flow rate at each lane $\mathrm{L}_{\mathrm{z}}$ ) as follows: 


$$
\begin{array}{llllll}
a_{L z}=1 & V_{L z}= & 0 & P\left(a_{L z}\right)= & 0 \\
a_{L z}= & 0 & V_{L z}= & 0 & P\left(a_{L z}\right)= & 1 \\
a_{L z}= & 1 & V_{L z}= & >0 & P\left(a_{L z}\right)= & x_{L z} \\
a_{L z}= & 0 & V_{L z}= & >0 & P\left(a_{L z}\right)= & \left(1-x_{L z}\right)
\end{array}
$$

where $x_{L z}$ is the degree of utilization as defined in the next equation 4. According to HCM (2000), at a generic subject approach, the probability for each degree-of-conflict case $P(i)$ can be computed using the degree of utilization $\left(x_{L z}\right)$ of each lane on the conflicting approach. When the arrival rate in the considered lane is $V_{L z}$ (veh/s), the degree of utilization is computed by the following equation:

$$
x_{L z}=\frac{V_{L z} \times h_{d, L z}}{3600}
$$

Table 1. Degree-of-conflict cases and probability of occurrence at a multilane not conventional roundabout

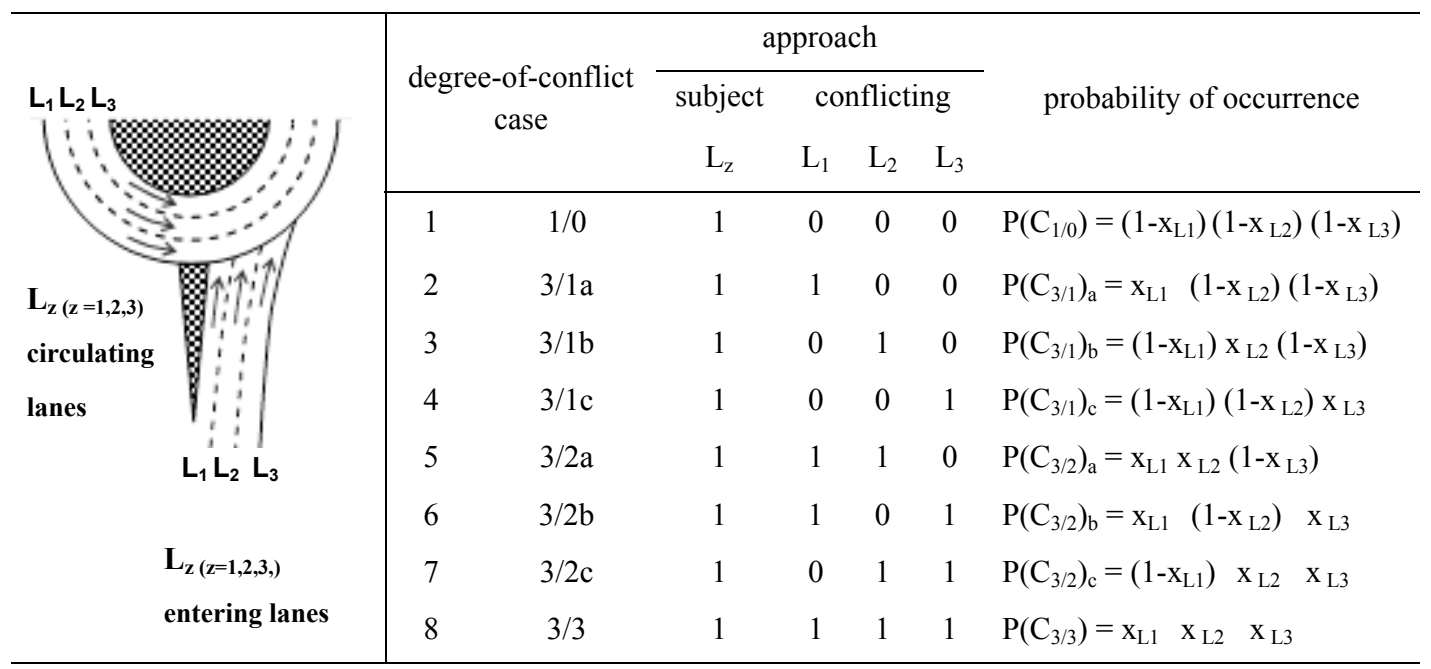

Note: 1 denotes presence of a vehicle; 0 denotes absence of vehicle.

Description: Table 1 shows eight combinations of degree of conflict cases and the probability of occurrence of each degree of conflict case at an approach with three entering/circulating lanes. Based on the aforesaid, for the case taken into account (a multilane not conventional roundabout with three circulating/entering lanes, corresponding to eight combinations of degree of conflict cases), the headway between consecutively departing subject approach vehicles (the entering lanes or the circulating lanes in turn) can be expressed by equation 1 , as follows:

$$
\begin{aligned}
\left(h_{d}\right)_{L z}=\sum_{i=1}^{8} P(i) \cdot\left(h_{s i}\right)_{L z} & =P\left(C_{1 / 0}\right) \cdot\left(h_{S 1 / 0}\right)_{L z}+\sum_{i=2}^{4} P\left(C_{3 / 1}\right)_{i} \cdot\left(h_{S 3 / 1}\right)_{L z, i}+\sum_{i=5}^{7} P\left(C_{3 / 2}\right)_{i} \cdot\left(h_{S 3 / 2}\right)_{L z, i} \\
& +P\left(C_{3 / 3}\right) \cdot\left(h_{S 3 / 3}\right)_{L z}
\end{aligned}
$$

As stated in section 2, traffic observations highlighted the difficulty of surveying directly unknown saturation headways by lane. Therefore, the analysis method proposed to evaluate capacity performances at multilane not conventional roundabouts requested the preliminary estimate of unknown saturation headways by lane. For this purpose, a marginal model based on the degree of conflict faced by the subject approach driver and calibrated on field observations was developed (see Giuffre et al., 2007b); given the presence of response correlation, regression parameters were estimated through Generalized Estimating Equations models (Hardin \& Hilbe, 2003). The model provided an estimation of the unknown behavioral parameters for not conventional roundabouts both with three lanes at entry and three lanes at circulating lanes, and with two lanes at entry and two lanes at circulating lanes.

Starting from the methodological base just outlined, a calculation algorithm was implemented to evaluate the performances at each approach through subsequent computational steps as it will be described in the following section 4 . 


\section{Steps to Model Capacity}

Drawing inspiration from the iterative procedure proposed for capacity estimates at all-way-stop-controlled intersections (HCM 2000), excepting for the need of a prior estimate of saturation headways from field observations, a calculation algorithm organized in 5 subsequent computational steps was developed in order to evaluate capacity at each entering/circulating lane of the approach for the type of roundabouts examined in this research. The interdependence of the traffic flows on intersection approaches created the need for iterative calculations to obtain significant estimates of capacity. For a given traffic flow matrix, the proposed capacity model allows to estimate headways $\left(\mathrm{h}_{\mathrm{d}}\right)$ between consecutive departing vehicles in the approach considered as the subject approach (the entry or the circulatory roadway); this assessment can be conducted for each lane at entry or for each lane at the circulatory roadway. According to Kyte et al. (1997), also at a lane of a not conventional roundabout characterized by a central island with a large diameter and by two (or more) entering and circulating lanes, capacity can be defined as the maximum throughput flow rate on an approach given the distribution of flow rates by lane on the other intersection approach (or the antagonist approach). The 5-step of the proposed procedure to compute capacity at each approach lane are as follows:

step 1 collect data input

the first step concerns input data to be acquired for estimating departure headways $\mathrm{h}_{\mathrm{d}, \mathrm{Lz}}$; data include the number of lanes at entries and in circulatory carriageway, traffic volumes per approach and per lane, turning and through movements counts from shared lanes also useful to estimate saturation headways;

step 2 assess probability states

after the identification of the degree-of-conflict cases, the step includes calculating the degree of utilization by lane and the probability of each degree-of-conflict case;

step 3 compute saturations headways

basic saturation headway and saturation headway adjustment factor are summed; according to the procedure developed by Giuffre et al. (2007b) to estimate saturation headways, it must be clarified that saturation headways (which are needed for the estimation of $\mathrm{h}_{\mathrm{d}, \mathrm{Lz}}$ ) can be observable only in the degree-of-conflict cases (1/0) and in the simplest combination of the degree of conflict case $(3 / 1)_{i}(\mathrm{i}=\mathrm{a}, \mathrm{b}, \mathrm{c})$; unknown saturation headways for the other combinations of degree-of-conflict cases $(3 / 2)_{\mathrm{i}(\mathrm{i}=\mathrm{a}, \mathrm{b}, \mathrm{c})}$ and $(3 / 3)$ may be estimated through a regression model whose predictive reliability has to be validated starting from traffic observations at approach lanes;

step 4 compute departure headway by lane at the subject approach

in this step iterative calculations are required due to traffic flows at approaches are interdependent: the departure headway computed in each iteration for the subject approach (the entry or the circulating lanes) is the initial value in the next iteration for the conflicting approach (when it becomes the subject approach in turn); the iteration has to be repeated until headways between two subsequent iterations differ less than $0.1 \mathrm{~s}$;

step 5 estimate approach capacity

the capacity at a lane can be finally computed. The capacity calculation assumes that the traffic flow demand matrix remains constant except for the flow rate which affects the lane where capacity should be calculated, or namely that the capacity of the subject approach is computed under the assumption that the flows on the conflicting lanes are constant. Under an assigned hypothesis of the increment, the given flow rate on the subject lane from time to time considered is increased, maintaining constant traffic volumes both at the conflicting lanes and in the adjacent lanes to the one for which capacity is being calculated; once the degree of utilization $(x)$ on any one lane has been reached 1 , convergence will be produced and the final value of the subject approach flow rate can be considered the maximum throughput or the capacity of the considered lane;

These considerations suggest that capacity of a lane at a multilane not-conventional roundabout, known geometric characteristics of approaches and the distribution of traffic volumes per lane interacting with the subject approach traffic streams, is the maximum value of the entering flow rate beyond which congestion occurs. 


\section{Application of the Capacity Analysis Method to a Case Study}

In order to apply the proposed algorithm for estimating capacity, a multilane not-conventional roundabout with large diameter and three lanes at entry and in circulatory carriageway, belonging to the road network of Palermo, Italy, was considered. More details on salient features of the intersection, traffic observations and analysis of field data are reported in Giuffre et al. (2007b). Here it refers briefly that to explain the proposed procedure, attention was focused on west entry of the intersection. 20 different operational conditions were considered; for a period of about two minutes each observation was made and recorded by lane. Departure headways and conflicting volumes for entering and circulating vehicles at the approach selected as case study are summarized in Tables 2. A brief description of the proposed procedure developed to determine saturation headways by lane $\left(\mathrm{h}_{\mathrm{si}}\right)$ will be referred in sub-section 5.1; results of the iterative method for deriving entry capacity values at the selected case study will shown in the following sub-section 5.2.

Table 2. Observed departure headways and conflicting volumes at the approach selected as case study

\begin{tabular}{lccccccc}
\hline \multirow{2}{*}{$\left(\mathrm{h}_{\mathrm{d}}\right)_{\mathrm{Lz}}$} & \multirow{2}{*}{ departure headways, $\mathrm{s}$} & \multicolumn{3}{c}{ circulatory roadway } & \multicolumn{3}{c}{ entry } \\
\cline { 2 - 8 } & $\min$ & $\max$ & $\operatorname{mean}$ value & $\min$ & $\max$ & mean value \\
\hline$\left(\mathrm{h}_{\mathrm{d}}\right)_{\mathrm{L} 1}$ & 2.75 & 10.2 & 6.63 & 0.73 & 10.38 & 5.64 \\
$\left(\mathrm{~h}_{\mathrm{d}} \mathrm{L}_{\mathrm{L} 2}\right.$ & 2.15 & 8.85 & 4.83 & 0.45 & 7.29 & 3.38 \\
$\left(\mathrm{~h}_{\mathrm{d}}\right)_{\mathrm{L} 3}$ & 1.3 & 5.47 & 3.16 & 0.4 & 4.32 & 2.25 \\
\hline \multirow{2}{*}{$(\mathrm{v})_{\mathrm{Lz}}$} & \multirow{2}{*}{ conflicting volume, veh/h } & \multicolumn{3}{c}{ circulatory roadway } & \multicolumn{3}{c}{ entry } \\
\cline { 2 - 8 } & \multicolumn{2}{c}{$\min$} & $\max$ & mean value & min & max & mean value \\
\hline \multirow{2}{*}{$(\mathrm{v})_{\mathrm{L} 1}$} & 240 & 540 & 348 & 150 & 510 & 321 \\
$(\mathrm{v})_{\mathrm{L} 2}$ & 390 & 780 & 574 & 270 & 630 & 462 \\
$(\mathrm{v})_{\mathrm{L} 3}$ & 270 & 900 & 576 & 360 & 810 & 643 \\
\hline
\end{tabular}

\subsection{Determining Saturation Headways}

In order to determine unknown behavioral parameters from traffic observations, i.e. saturation headways by lane, a marginal model based on the degree-of-conflict in which the subject approach driver incurs was estimated from traffic observations at lanes of the antagonist approach. Based on field observations, the procedure proposed by Giuffrè et al. (2007b) assumes that saturation headways are observable only in the degree-of-conflict case 1/0 and in the simplest combination of the degree of conflict case 3, i.e. in the combinations (3/1) Lz. Omitting the mutual effect of the vehicles' position at the conflicting approach with regard to the corresponding effect at the subject approach, for the scheme of intersection considered in this research, the number of parameters to be estimated are limited to $\left(\mathrm{h}_{\mathrm{S} 3 / 2}\right)_{\mathrm{Lz}}$ and $\left(\mathrm{h}_{\mathrm{S} 3 / 3}\right)_{\mathrm{Lz}}, 6$ parameters in total. The generalized model was put in the following form:

$$
\left(h_{d}\right)_{L z}=P\left(C_{1 / 0}\right) \cdot\left(h_{S 1 / 0}\right)_{L z}+\left(h_{S 3 / 1}\right)_{L z} \cdot \sum_{i=2}^{4} P\left(C_{3 / 1}\right)_{i}+\left(h_{S 3 / 2}^{*}\right)_{L z} \cdot \sum_{i=5}^{7} P\left(C_{3 / 2}\right)_{i}+P\left(C_{3 / 3}\right) \cdot\left(h_{S 3 / 3}^{*}\right)_{L z}
$$

where $h_{s i}$ denoted by a star symbol are unobservable and may be estimated through a regression model involving probability of occurrence of degree-of-conflict cases $3 / 2$ and $3 / 3$ as regressor of the response variate $\left(h_{d}\right)_{L z}$.

Considering that $\left(\mathrm{h}_{\mathrm{d}}\right)_{\mathrm{Lz}, \mathrm{k}}$ is the elementary observation of the response variate and assuming for it a normal distribution, the above positions lead to write:

$$
\begin{gathered}
\left(h_{d}\right)_{L z, k} \sim N\left(\mu, \sigma^{2}\right) \\
\mu=E\left[\left(h_{d}\right)_{L z, k} / P_{k}\right]=o_{k}+P_{k}^{\prime} \cdot\left(h_{S}^{*}\right)_{L z}
\end{gathered}
$$

where:

$$
o_{k}=P\left(C_{1 / 0}\right)_{k} \cdot\left(h_{S 1 / 0}\right)_{L z}+\left(h_{S 3 / 1}\right)_{L z} \cdot \sum_{i=2}^{4} P\left(C_{3 / 1}\right)_{i}
$$




$$
\begin{aligned}
& \mathbf{P}_{k}^{\prime}=\left[\sum_{i=5}^{7} P\left(C_{3 / 2}\right)_{i}, P\left(C_{3 / 3}\right)\right] ; \\
& \left(\mathbf{h}_{S}^{*}\right)_{L z}^{\prime}=\left[\left(h_{S 3 / 2}^{*}\right)_{L z},\left(h_{S 3 / 3}^{*}\right)_{L z}\right]
\end{aligned}
$$

The intrinsic correlation of $h_{d}$ observations at approaches within each operational condition did not permit that regression parameters were estimated efficiently by likelihood based methods (Diggle et al., 2002; Fitzmaurice et al., 1993), but quasi-likelihood methods were used (Fitzmaurice, 1995; McCullagh \& Nelder, 1989). For estimating saturation headways from traffic observations, a marginal model was implemented in GenStat using Generalized Estimating Equations models (as formulated by Zeger et al., 1988). Sample correlation analysis, functional form selection between the dependent variable (i.e. the response variate) and the independent variable (i.e. the explanatory variate) and model validation are reported in Giuffrè et al. (2007b).

Saturation headways by lane are now computable as sum of a base saturation headway by lane and of a saturation headway adjustment factor related to through traffic movements (i.e. the share of these maneuvers in the considered lane) due to their influence on the departure headway, by the following:

$$
h_{s i, L z}=h_{s i-b a s e, L z}+h_{T H i, L z} P_{T H i, L z}
$$

where:

$h_{\text {si-base, } L z}=$ saturation headway for the degree-of-conflict case $i$, by lane;

$h_{T H, L z}=$ headway adjustment for through traffic movements, by lane;

$P_{T H, L Z}=$ proportion of through traffic movements on the approach, by lane;

$i=$ generic combination of $n$ degree of conflict cases.

Saturation headways by degree-of-conflict case, approach and lane at the not conventional roundabout selected

\begin{tabular}{|c|c|c|c|c|c|c|c|}
\hline \multicolumn{8}{|c|}{ not conventional roundabout with three lanes at entry and three circulating lanes } \\
\hline \multirow{2}{*}{$\begin{array}{l}\text { Degree of conflict } \\
\text { case }\end{array}$} & \multirow{2}{*}{$\mathrm{h}_{\mathrm{s}}$} & \multicolumn{3}{|c|}{ circulatory roadway } & \multicolumn{3}{|c|}{ entry } \\
\hline & & $\mathrm{L}_{1}$ & $\mathrm{~L}_{2}$ & $\mathrm{~L}_{3}$ & $\mathrm{~L}_{1}$ & $\mathrm{~L}_{2}$ & $\mathrm{~L}_{3}$ \\
\hline \multirow{2}{*}{$1 / 0$ or $(3 / 1)_{\mathrm{i}}$} & $\mathrm{h}_{\text {si-base }}$ & 1.99 & 1.42 & 1.13 & 1.73 & 1.16 & 0.87 \\
\hline & $\mathrm{h}_{\mathrm{TH}}$ & - & - & - & - & - & - \\
\hline \multirow{2}{*}{$(3 / 2)_{\mathrm{i}}$ plus $(3 / 3)$} & $\mathrm{h}_{\text {si-base }}$ & 8.53 & 5.77 & 4.10 & 6.53 & 3.77 & 2.10 \\
\hline & $\mathrm{h}_{\mathrm{TH}}$ & 1.73 & 1.73 & 1.73 & 1.73 & 1.73 & 1.73 \\
\hline \multicolumn{8}{|c|}{ not conventional roundabout with two lanes at entry and two circulating lanes } \\
\hline \multirow{2}{*}{$\begin{array}{l}\text { Degree of conflict } \\
\text { case }\end{array}$} & \multirow{2}{*}{$\mathrm{h}_{\mathrm{s}}$} & \multicolumn{3}{|c|}{ circulatory roadway } & \multicolumn{3}{|c|}{ entry } \\
\hline & & \multicolumn{2}{|c|}{$\mathrm{L}_{1}$} & $\mathrm{~L}_{2}$ & $\mathrm{~L}_{1}$ & \multicolumn{2}{|r|}{$\mathrm{L}_{2}$} \\
\hline \multirow{2}{*}{$1 / 0$ or $(3 / 1)_{i}$} & $\mathrm{~h}_{\text {si-base }}$ & \multicolumn{2}{|c|}{1.61} & 1.61 & 1.61 & \multicolumn{2}{|r|}{1.61} \\
\hline & $\mathrm{h}_{\mathrm{TH}}$ & \multicolumn{2}{|c|}{-} & - & - & \multicolumn{2}{|r|}{-} \\
\hline \multirow{2}{*}{$(3 / 2)_{\mathrm{i}}$ plus $(3 / 3)$} & $\mathrm{h}_{\text {si-base }}$ & \multicolumn{2}{|c|}{9.53} & 6.61 & 6.92 & \multicolumn{2}{|r|}{4.00} \\
\hline & $\mathrm{h}_{\mathrm{TH}}$ & \multicolumn{2}{|c|}{1.12} & 1.12 & 1.12 & \multicolumn{2}{|r|}{1.12} \\
\hline
\end{tabular}
as case study are reported in Table 3.

Table 3. Saturation headways by degree-of-conflict case, approach and lane for the case study

This table shows behavioral parameters both for the roundabout with three lanes at entry and three lanes at circulating lanes and for the roundabout with two lanes at entry and two circulating lanes. As anticipated above, estimates in Table 3 were obtained considering equation (6) as a regression model and assuming that saturation headways were observed directly only in the degree-of-conflict cases $1 / 0$ and in the simplest combination of the degree of conflict case $3 / 1_{\mathrm{i}(i=\mathrm{a}, \mathrm{b}, \mathrm{c})}$, and were taken equal to their respective average values. The most appropriate regressors of the residual response variate (i.e. unobservable parameters $h_{\mathrm{si}}$ ) were estimated considering together the probability of occurrence of degree-of-conflict cases $3 / 2_{\mathrm{i} i=\mathrm{a}, \mathrm{b}, \mathrm{c})}$ and $3 / 3$. 


\subsection{Deriving Entry Capacity Values from Field Data}

It must first start by saying that due to the complexity of the iterative procedure proposed for the calculation of the capacity at multilane not-conventional roundabouts, where drivers follow a pattern of consensus of right-of-way, together with the peculiarity of the way of working and operating limits of the intersection scheme selected in this research as case study, it was not possible to obtain a generalized representation of capacity versus conflicting volumes. Nevertheless, in order to represent the functional link between capacity values for each lane (at entry and at circulatory roadway) and conflicting volumes, some assumptions were taken: first, three lanes both at entry and at circulatory roadway were considered; then, the outer lane at entry was considered not conditioned by any conflicting volumes; finally, the initial traffic volumes both at entry and at circulatory carriageway were considered to have the same total values and they were assumed equally shared among lanes. Under these hypotheses, applying the iterative procedure for the calculation of the capacity explained in section 4, it was possible to estimate capacity values versus conflicting volumes, both when the entry is the subject approach, and when the circulatory roadway is the subject approach in turn. Results of the proposed computational algorithm in the specified set of conditions in which they were obtained and only when the entry is the subject approach are reported in Table 4; more specifically, values in Table 4 are referred only to the inner entry lane $\left(\mathrm{L}_{1}\right)$ and to the median entry lane $\left(\mathrm{L}_{2}\right)$ that are characterized by a high degree of conflict; the outer entry lane $\left(\mathrm{L}_{3}\right)$ was neglected because vehicular movements were considered not conditioned by any conflicting volumes according to the second assumption above reported. With reference to values in Table 4, for example, when the traffic volume at the entry lane $\mathrm{L}_{1}$ reaches a capacity value equal to $1780 \mathrm{veh} / \mathrm{h}$, the corresponding total circulating volume is equal to $600 \mathrm{veh} / \mathrm{h}$ and it is divided equally among lanes. At the same time, when the volume on the subject approach lane (lane $\mathrm{L}_{1}$ ) is gradually increased, traffic flow on the other entry lane is constant and equal to the initial value $(300 \mathrm{veh} / \mathrm{h})$.

Table 4. Entry lane capacity $v s$ conflicting volumes at a multilane roundabout

\begin{tabular}{ccc}
\hline $\begin{array}{c}\text { Qcr } \\
{[\mathrm{veh} / \mathrm{h}]}\end{array}$ & $\begin{array}{c}\mathrm{C}_{\mathrm{e} 1}\left(\text { lane } \mathrm{L}_{1}\right) \\
{[\mathrm{veh} / \mathrm{h}]}\end{array}$ & $\begin{array}{c}\mathrm{C}_{\mathrm{e} 2}\left(\text { lane } \mathrm{L}_{2}\right) \\
{[\mathrm{veh} / \mathrm{h}]}\end{array}$ \\
\hline 100 & 2090 & 3090 \\
200 & 2060 & 3060 \\
300 & 2010 & 2990 \\
400 & 1960 & 2860 \\
500 & 1870 & 2710 \\
600 & 1780 & 2540 \\
700 & 1670 & 2290 \\
800 & 1520 & 1940 \\
900 & 1330 & 1470 \\
1000 & 1100 & 1120 \\
1100 & 860 & 860 \\
1200 & 670 & 670 \\
\hline \multirow{2}{*}{ Data fit: } & $y=-0.0012 x^{2}+0.2314 x+2063.2$ & $y=-0.0017 x^{2}-0.186 x+3182.3$ \\
& $R^{2}=0.9984$ & $R^{2}=0.9881$ \\
\hline
\end{tabular}

Note: " $e$ " in Ce means entry; "cr" in Qcr means circulatory carriageway

Similar considerations apply to the values in Table 5, representing entry lane capacity values $v s$ conflicting volumes at a not-conventional roundabout with two lanes at entry and two lanes at circulating lanes, only when the entry is the subject approach. These values were calculated to consider also real cases in which vehicles approaching the intersection from the outer entry lane and from the inner lane of the circulatory roadway are not conditioned by conflicting traffic. Also in this case to obtain the functional link between capacity values for each lane at entry and conflicting volumes, some assumptions were adopted: besides having already assumed two lanes at entry and two lanes at circulatory roadway, it was also considered that traffic volumes coming from the outer lane at entry and moving on the inner lane at circulatory roadway do not affect vehicles transiting on the adjacent lanes and, in turn, are not affected; moreover, it was also assumed that the initial traffic volumes both at 
entry and at circulatory carriageway have the same total values and they are equally shared among lanes. For this case saturation headways were estimated through the procedure mentioned above and, as already said, results are depicted in Table 3. For example, when the traffic volume at the entry lane $\mathrm{L}_{1}$ reaches a capacity value equal to $1990 \mathrm{veh} / \mathrm{h}$ the corresponding total circulating volume is equal to $500 \mathrm{veh} / \mathrm{h}$ and it is divided equally between the two lanes (see Table 5). Moreover, while the volume on the examined subject approach lane $\left(\mathrm{L}_{1}\right)$ is gradually increased, the flow on the other approach lane $\left(\mathrm{L}_{2}\right)$ is constant and equal to the initial value $(250 \mathrm{veh} / \mathrm{h})$. For the intersections examined in this study, capacity values at entry approach obtained through the proposed method were compared to capacity values as calculated by Kimber linear model (1980), regarding capacity at very large diameter roundabouts, and to capacity values modeled by Brilon-Wu (1996), as referred by the User Manual of KREISEL (Germany) and reported by the HBS 2001 (FGSV 2001, Handbook for assessing road traffic facilities. Koln: Forschungsgesellschaft fur das Strassen und Verkehrswesen).

Table 5. Entry lane capacity vs conflicting volumes at a two-lane roundabout

\begin{tabular}{ccc}
\hline $\begin{array}{c}\text { Qcr } \\
{[\mathrm{veh} / \mathrm{h}]}\end{array}$ & $\begin{array}{c}\mathrm{C}_{\mathrm{e} 1}\left(\text { lane } \mathrm{L}_{1}\right) \\
{[\mathrm{veh} / \mathrm{h}]}\end{array}$ & $\begin{array}{c}\mathrm{C}_{\mathrm{e} 2}\left(\text { lane } \mathrm{L}_{2}\right) \\
{[\mathrm{veh} / \mathrm{h}]}\end{array}$ \\
\hline 100 & 2250 & 2250 \\
200 & 2220 & 2220 \\
300 & 2170 & 2210 \\
400 & 2100 & 2160 \\
500 & 1990 & 2090 \\
600 & 1860 & 2000 \\
700 & 1700 & 1850 \\
800 & 1440 & 1560 \\
900 & 1150 & 1200 \\
1000 & 880 & 880 \\
1100 & 670 & 670 \\
1200 & 600 & 601 \\
\hline Data fit $y=-0,0012 x^{2}-0,1327 x+2311,6=-0,0016 x^{2}+0,4529 x+2233,7$ \\
\end{tabular}

Figure 1 shows this comparison for the case of three circulating lanes and two entering lanes; conversely Figure 2 shows the comparison for the case of two circulating lanes and two entering lanes. Models used for the comparison use total circulating flow rate to determine the entry capacity per approach. The Kimber linear regression model estimates higher values than those computed by the capacity model developed by Brilon-Wu (1996) in the whole range of variation of the circulating flow rate. From Figure 1, by way of example, when the $\mathrm{Q}_{\mathrm{cr}}$ value matches $600 \mathrm{veh} / \mathrm{h}$, the corresponding $\mathrm{Ce}(1)$ and $\mathrm{Ce}(2)$ approach capacity values are equal to 2080 $\mathrm{veh} / \mathrm{h}$ and $2840 \mathrm{veh} / \mathrm{h}$, respectively; considering, for example Ce(1) values, the value of $2080 \mathrm{veh} / \mathrm{h}$ was obtained adding the capacity value reached at lane $\mathrm{L}_{1}$ during the incremental phase (and equal to $1780 \mathrm{veh} / \mathrm{h}$ ) to the initial traffic volume (300 veh/h), stayed constant in the adjacent entering lane $\mathrm{L}_{2}$. 


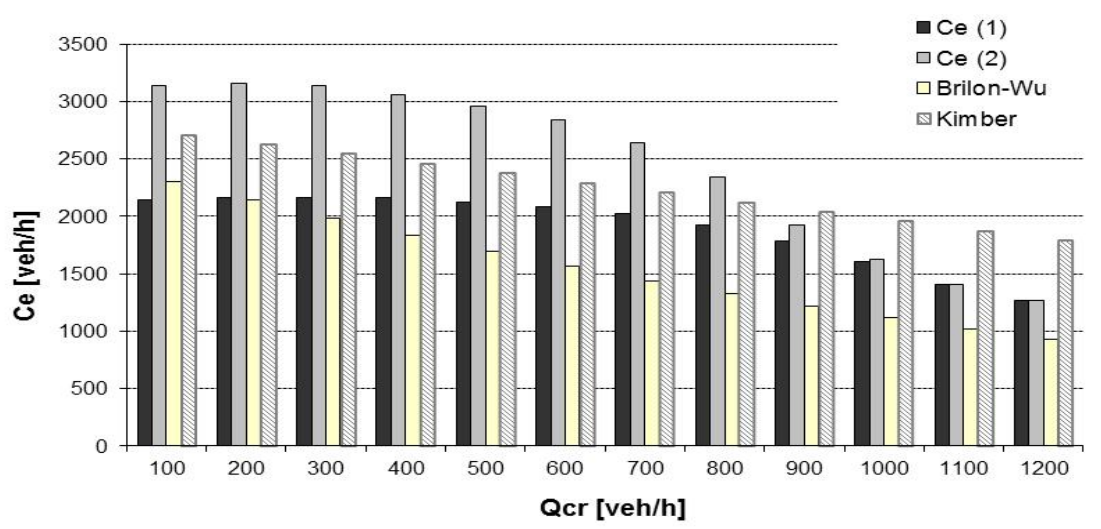

Figure 1. Comparing model capacity to experimental data at a multilane roundabout

Note: Capacities by Brilon-Wu model (1996) are computed through ne/ncr =2/3

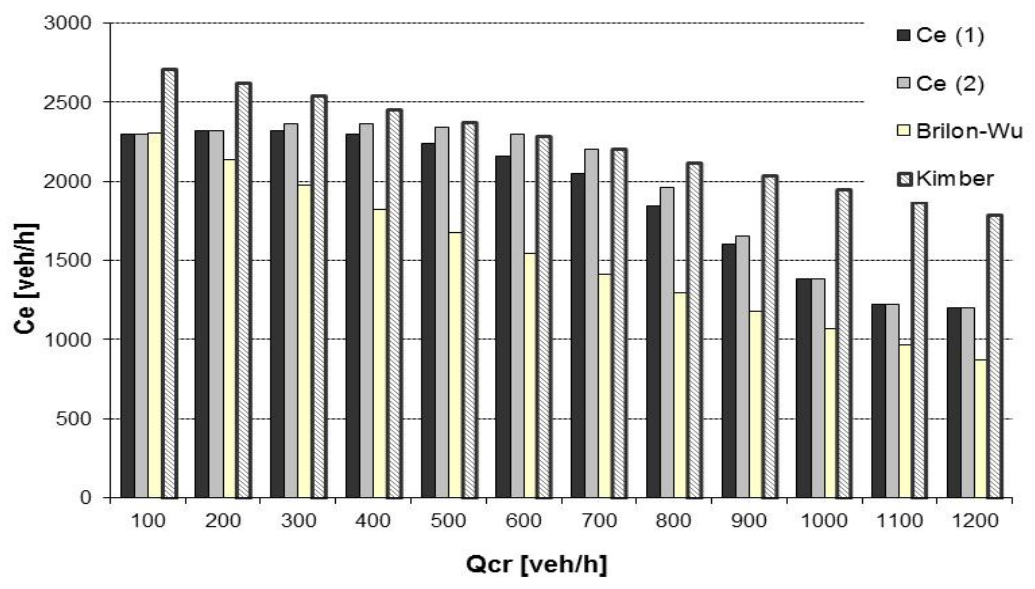

Figure 2. Comparing model capacity to experimental data at a two-lane roundabout

Note: Capacities by Brilon-Wu model (1996) are computed through ne/ncr $=2 / 2$

Basing on what said, the gain of capacity imputable to the consensus pattern of right-of-way between entering and circulating vehicles at the roundabout selected as a case study regards circulating flow values within their entire range of variability. Comparing model capacities to experimental data at a multilane not-conventional roundabout allows us to deduce that proposed method seems to be able for qualifying and quantifying capacity parameters at not-conventional roundabouts here examined.

\section{Summary and Conclusions}

Models developed for modern roundabouts are inappropriate to assess reliably operating conditions at infrastructural schemes of intersections where differences in terms of geometric layout are present and operational modes from the typical to the atypical are coexisting. At roundabouts under analysis it was observed that users do not respect the nominal operating rule, but they behave alternating the right-of-way with other users coming from antagonist approaches.

Within the limits of the analyzed cases, the analogy with all-way stop-controlled intersections allowed to interpret experimental data and to develop a capacity model useful to quantify and qualify functional aspects of not conventional roundabouts. The application to a multilane not conventional roundabout, examined as a case study, allowed to illustrate both how to derive the capacity model and to apply the algorithm to evaluate performances at entry through its articulation in subsequent computational steps.

The method can be adapted both to take account of specific geometric layouts, for which usual models based on the gap-acceptance theory are not applicable, and to include factors that can affect operating conditions under 
consideration (lane occupied by the vehicle at approaches, presence of heavy vehicles, type of movement, etc.). The access to these parameters is the preliminary stage to the development of an analytical model for estimating the level-of-service experienced by users at not-conventional roundabouts.

\section{References}

Diggle, P. J., Heagerty, P., Linan, K. Y., \& Zeger, S. L. (2002). Analysis of longitudinal data (2 ${ }^{\text {nd }}$ ed.). Oxford University Press, Oxford UK.

Fitzmaurice, G. M., Laird, N. M., \& Rotnitzky, A. (1993). Regression models for discrete longitudinal responses. Statistical Science, 8, 284-309. http://dx.doi.org/10.1214/ss/1177010899

Fitzmaurice, G. M. (1995). A caveat concerning independence estimating equations with multivariate binary data. Biometrics, 51/1995, 309-317. http://dx.doi.org/10.2307/2533336

Giuffrè, O., Granà, A., Giuffrè, T., \& Marino, R. (2007a). A generalized model for analyzing operational conditions at intersections in urban areas. Proc. of the $3^{\text {rd }}$ Urban Street Symposium, pp. 1-14, June 24-27, 2007 Seattle, Washington, U.S.A.

Giuffrè, O., Granà, A., Giuffrè, T., \& Marino, R. (2007b). Modeling traffic operations and driver' behavioral parameters at not-conventional roundabouts. A theoretic-experimental approach. Proc. of the 86th TRB Annual Meeting. January 21-25, 2007. Washington, D.C., U.S.A pp. 1-16.

Granà, A., \& Giuffrè, T. (2005). Performance analysis of roundabouts in strongly constrained environment. Case studies in urban areas. 2005 National Roundabout Conference, Vail, Colorado, May 22-25, 2005, pp. 1-9.

Hardin, J. W., \& Hilbe, J. M. (2003). Generalized Estimating Equations. London: Chapman \& Hall/CRC Press (2003). ISBN 9781584883074

Kimber, R. M. (1980). The traffic capacity of roundabouts. Crowthorne, Berkshire, UK: TRRL Laboratory, Report 942.

Kyte, M., Tian, Z., Mir, Z., Hameedmansoor, Z., Kittelson, W., Vandehey, M., Robinson, B., Brilon, W., Bondzio, L., Wu, N., \& Troutbeck R. (1997). Capacity and level of service at unsignalized intersections, NCHRP Web Doc 6: Final Report, 2, All-Way Stop-Controlled Intersections. http://www.nap.edu/books/nch006/html

Kyte, M., \& List, G. (1999). A capacity model for all-way stop-controlled intersections based on stream interactions. Transportation Research Part A: Policy and Practice 33(3), 313-335. http://dx.doi.org/10.1016/S0965-8564(98)00043-3

McCullagh, P., \& Nelder, J. A. (1989). Generalized linear models ( $2^{\text {nd }}$ ed.). London, UK: Chapman and Hall.

Richardson, A. J. (1987). A delay Model for Multiway Stop-Sign Intersections. Transportation Research Record $1112,107-114$.

Rodegerdts, L., Blogg, M., Wemple, E., Myers, E., Kyte, M., Dixon, M., ... Carter, D. (2010). Roundabouts: An Informational Guide ( $2^{\text {nd }}$ ed.). Washington DC, USA: Transportation Research Board of the National Academies, NCHRP Report 672.

Wu, N. (2000). Determination of Capacity at All-Way Stop-Controlled Intersections. Journal Transportation Research Record: Journal of the Transportation Research Board, 1710/2000, 205-214. http://dx.doi.org/10.3141/1710-24

Zeger, S. L., Liang, K. Y., \& Albert, P. S. (1988). Models for longitudinal data: A generalized estimating equation approach. Biometrics, 44, 1049-1060. http://dx.doi.org/10.2307/2531734 